\title{
THE ROLE OF WEALTH IN THE EXPERIENCE OF QUALITY OF LIFE OF THE SEMI-AFFLUENT INVESTOR
}

\author{
L M MEYER \\ J S UYS \\ jsu@rau.ac.za \\ Department of Human Resource Management \\ University of Johannesburg
}

\begin{abstract}
In an attempt to assist semi-affluent investors' best use their wealth to improve their lives, this study explores the role of wealth in the experience of quality of life. Seven clients of a financial advisory firm based in the U.S.A, were interviewed using the repertory grid technique. Through an interpretive analysis wealth was found to influence the experience of quality of life in the way that it was used to satisfy individual material and security needs; shape growth and relatedness needs and influence how respondents establish, maintain and verify their identity.
\end{abstract}

Key words

Semi-affluent investor, financial advice, wealth, quality of life, repertory grid

The financial advisory business, specifically the business of providing advice to the semi-affluent investor, is on the brink of a major evolution. Its staggering growth rate over the past five years, a compounded annual growth rate of $34 \%$, is unsustainable (Hurley et al., 2004).

A contributing factor to this evolving situation is the commoditization of goods and services. This is due in large measure to the fact that the financial services industry is and also will increasingly be a lucrative class action litigation target for lawyers. The response of the industry to these attacks is conformity through meeting compliance requirements. Compliance issues along with the increased use of technology are commoditizing many individual services provided by advisory firms and diminishing their value-add. Increasingly financial advisors are unable to compete on the basis of low margin commoditized products or services and are losing their ability to differentiate themselves (Bulazo, 2004; Hurley et al., 2004; Valli, 2004; Zalewski, 2004).

The resultant commoditization of goods and services is also alienating the client who is increasingly seeking individual value- and meaning-centered advice (Sullivan, 2004). Clients who are better informed than in the past and demanding better advice for their money are highly frustrated with the reduced value creation that is taking place in a highly commoditized industry and are demanding "psychological self-determination," a term coined by Zuboff and Maxmin (2002, p. 33). That is the ability to feel that they have greater ownership of their personal and financial futures. This reflects a shift in the structure of consumption to what Zuboff and Maxmin (2002, p.171) call the individuation of consumption. The message from the client now is "I am willing to buy that which will enable me to live an ever more individuated life. I am willing to buy that which will enable me to make myself, to know myself, and to be myself. I am willing to buy aid and succour in my quest for psychological self-determination".

In response to these changes in the nature of the industry and the client, niche financial advisory firms are shifting their business models from traditional transaction-based compensation systems to fee-based programs in order to compete for semi-affluent clients. A move from commoditybased selling to solutions-based counseling. What is required then of the future dominant advisory firm is an understanding of their clients from more than just a financial perspective if they intend to be able to tailor their advice to each client's specific needs (Slowik et al., 2000).

Understanding clients, however, is a multi-faceted challenge. For most semi-affluent clients, wealth is just a means to an end. They are not interested in good investment products Rather good investment products serve only as potential solutions to clients' problems (Hurley et al., 2004; Slowik et al., 2000). However the experience of many financial advisors is that their clients are far better at building wealth than at employing it to meet their goals and needs. Although clients are expecting, nay demanding psychological selfdetermination, the ability to feel that they have greater ownership of their personal and financial futures, they, the clients, often seem unclear and unable to define what they wish for and aspire to in their personal and financial futures. With many clients struggling with existential questions around: What is the meaning of my life? What is my purpose? What do I value? What is important to me? (Bulazo, 2004; Dressel, 2004; Valli, 2004; Zalewski, 2004).

In response to this, a niche financial advisory firm based in the United States, dealing only with semi-affluent investors is exploring the area of "personal capital" as a strategic opportunity to better support their clients. Personal capital involves how wealth affects (both positively and negatively) clients' quality of life. Personal capital services are designed to help clients best use their wealth to improve their lives (Slowik et al., 2000).

The purpose of this study then is to explore the role of wealth in the client's experience of quality of life. How do a group of American semi-affluent investors understand the personal meaning of their wealth and its value in how they experience living?

\section{Definitions}

An individual or household is considered to be semi-affluent should it have a total net worth greater than one million dollars and less than ten million dollars (Hurley et al., 2004).

When it comes to a definition of wealth it is important to distinguish between money and wealth. For economists, money is a particular commodity that comes to be used as a dependable medium of exchange. Wealth however can be held in the form of money, (money in your pocket or checking account) or in other forms such as a house, stock or even art on a wall (Finn, 1992). Wealth can also be viewed from an individual personal definition of welfare perspective. However for the purposes of this paper which has as its context the financial advisory firm's want to understand the role of material wealth in their clients' experience of quality of life, wealth will therefore be understood from a financial perspective as reflected in the definition of Finn. The individual's perception of welfare is explored more fully in how one understands quality of life. 
When it comes to a definition for quality of life it is also important to distinguish between two concepts, standard of living, and quality of life. Standard of living is conventionally defined by the principle of "consumption of material goods", the higher the level of such consumption, the higher the standard of living (Diwan, 2000). Quality of life (QOL) is based on a completely different principle and is a problematic concept to define as different people value different things (Farquhar, 1995). Initially QOL definitions were based on measurable, objective indicators such as income, mortality, crime rates, but shortfalls in this approach led to the inclusion of more subjective variables for example, happiness and life satisfaction (Smith, 2000). In acknowledgment of the complexity of the concept, the World Health Organization (1998, p.551), defines QOL as “...an individual's perception of their position in life in the context of the culture and value systems in which they live and in relation to their goals, expectations, standards and concerns".

Zapf (1987, p. 47), similarly stresses the multidimensional character of the concept in that "...the QOL of individuals...is determined by the constellation of individual conditions of life and the components of subjective well being. The conditions of life include on the one hand, the dimension of security needs (having) such as income, education, health, accommodation and work and on the other hand the dimension of social needs (loving) such as family ties, social contacts and social and political participation. Subjective well being means the assessment, by the individual of specific conditions of life and life in general. These include hope, fear, happiness, loneliness, competences, insecurity and worries. Together these are the components of quality of life". More simply put, one could intuitively equate quality of life for an individual with "overall happiness or satisfaction with one's life" (Bernheim \& Heylighen, 2000, p. 325). QOL then refers to the evaluation of one's own life by an individual (Srivastava, Locke \& Bartol, 2001).

For the purposes of this paper then, the experience of QOL is understood to depend on some material goods as well as nonmaterialist values that are intrinsically subjective. It has to do with individual sense making in specific life contexts. QOL has to do with the expression of personal preferences, choices, decisions and considerations and the individual assessment of these within one's own life. Acknowledgement of this subjectivity is important when dealing with clients who, as stated earlier, have shifted into the individuation of consumption and are disenchanted with a commoditized approach to their needs.

To better assist these clients employ their wealth to meet their individualized goals and needs; this study seeks to understand how wealth affects the client's experience of quality of life. What unique role does wealth play in each client's assessment of their experience of living? How do clients make sense of the meaning of wealth in their lives? In exploring the role of wealth in the experience of quality of life, financial advisors will be better able to support their clients in optimally utilizing their wealth to improve their experience of quality of life.

\section{RESEARCH DESIGN}

Research Approach

There are a number of standardized item-based questionnaires for evaluating quality of life (QOL) which typically subdivide QOL into different domains that are captured by a validated set of selected items (Bernheim \& Heylighen, 2000). However, the purpose of this study is not to measure or test wealth as a statistical variable in QOL, but rather to understand the role of wealth in the experience of QOL. It is an attempt to understand and interpret the meaning of wealth to respondents in their experience of QOL.
The study is approached from a position where the researcher does not assume that she understands what the phenomenon of wealth means to the respondents in their experience of quality of life (Bodgan \& Biklen, cited in Schurink, 2004) and data analysis is based on interpretation of the meaning that respondents give to wealth. Therefore, the metatheory approach is phenomenological which resorts under the qualitative methodological paradigm (Babbie \& Mouton, 1998; Creswell, 1998).

Although there is no consensus on an exact definition of qualitative research, (Strauss \& Corbin, 1990), this study can be considered qualitative in that it is characterized by many of the attributes of such a research style. Firstly the context of the respondents is considered to be important. The focus of the study is on the semi-affluent investor linked to a specific financial advisory firm with all data gathering occurring in the respondents' own natural settings. The data gathered was descriptive and not numerical in nature and explored how the respondents negotiate meaning, make sense of their circumstances specifically in terms of what wealth means to each respondent in their experience of QOL. Analysis of the data was inductive and reflects familiarity with the respondents in the study (Schurink, 2004).

\section{Respondents}

Qualitative research requires that the data to be collected must be rich in description of people and places (Patton, cited in Schurink, 2004). For these reasons purposive sampling methods are used (Schurink, 2004). Using maximum variation sampling, a purposive method, members of the financial advisory firm who know their clients intimately identified seven respondents considered to be information rich sources, out of a possible 100 clients that they considered to reflect both unique cases, (in terms of gender, employment, how wealth was obtained) as well as that which is largely common to the group; they were all semi-affluent and in a similar age range. In this way a heterogeneous sample was purposefully selected reflecting unique cases as well as commonalities in experience (Schurink, 2004).

\section{Methods of Data gathering}

For the process of this enquiry to be qualitative, data gathering should be "...based on building a complex, holistic picture, formed with words, reporting detailed views of informants and conducted in a natural setting" (Creswell, 1994, p.1). Using this as a guideline as well as Mason's notion that qualitative research data gathering methods be flexible and sensitive to the social context in which data is generated (as cited in Schurink, 2004); the Repertory Grid Technique was selected as the means for data generation. This technique provides a structure for interviewing that allows respondents to describe the role of wealth in their experience of QOL in their own terms and in a time efficient manner, which was an important consideration given the time driven schedules of the respondent group.

Kelly (1963), the original proponent of Personal Construct Theory invented the Repertory Grid Technique as a way of enabling people to exhibit their construct systems. Implicit in Personal Construct Theory, is the notion that each individual holds a unique view of what the world looks like and how it operates. Constructs are ways of construing the world. They are the patterns or templates which individuals create in their sense making of their worlds (Kelly, 1963).Through the Repertory Grid Technique one gains an understanding of how the respondent perceives their world, in this case how the respondents understand the role of wealth in their experience of QOL.

Repertory Grid technique allows the researcher to in a sense draw a mental map of how the respondent views the world in a rigorous fashion. Observer bias is kept to a minimum as information is obtained during interviews with negligible input from the observer (Stewart, 1981). Respondents were asked to 
identify and describe three incidents/examples where money or a financially related issue had a positive effect on their experience of quality of life and two incidents where the effect of money or a financially related issue was experienced as negative or neutral. By asking respondents to compare these experiences, a highly personal, internal standard for QOL and the role of wealth in QOL is defined. This eliminates social desirability, trait and cultural biases, where people answer what they feel they are expected to do. This also avoids peer relativity, where people define their own situation relative not to personal standards, but to the distribution of the group to which they belong (Bernheim \& Heylighen, 2000).

\section{Procedure}

The respondents were invited to be part of the study after the nature and purpose of the study was explained to each of them. All respondents agreed to participate.

Repertory grid interviews took place in a structured interview format carried out on a single person face-to-face basis between the researcher and each respondent in natural settings of their choice. On average each interview lasted 60 to 90 minutes. Each interview began with an explanation of the purpose of the study, a description of the grid technique and a statement of the conditions of confidentiality and anonymity.

The interview process was guided by the suggested repertory grid processes of Kelly (1963), Stewart (1981) and Jankowicz (2004). The interview process began with the identification of elements. Element identification defines the kind of interview that will take place by focusing on the subject matter/topic which in this case focuses on the role of wealth in the experience of QOL. To identify these elements, respondents were asked to identify three incidents or events where money or a financially related issue (to cover all the facets of "wealth") had a positive effect on their experience of QOL. Examples of elements from the interviews included: buying a commercial property; a shopping spree in New York City; exchanging specific stock options; a company listing on the stock exchange. Respondents were then asked to identify two incidents or events where money or a financially related issue had a negative or neutral effect on their experience of QOL. Examples here included: a father's death when the respondent was 9 years old; not hiring a salesperson; selling a house to family members; buying a second car. These elements were grouped in three's and respondents are asked to identify ways in which two of the elements are similar yet different to the third. All possible grouping comparisons were made with the five elements. The result of this, are lists of bipolar distinctions which are called constructs. This information is documented in a grid format during the interview by the researcher. The identified constructs represent the dimensions the respondents use when they think about the elements and are the basic unit of description and analysis (Jankowicz, 2004). As the focus of this study is on the constructs and their meanings rather than on numbers, the interview ended at this point. Repertory grid interviews can proceed into a phase of ranking elements.

\section{Analysis of the data}

In grid analysis, the job according to Jankowicz (2004) is two fold: firstly to identify the respondent's meanings and secondly to draw whatever implications seem to be appropriate to the purpose of the study.

The first step in analysis is description, outlining what exists to gain an understanding of what the respondent is expressing. To achieve this, a process analysis and then an eyeball analysis were conducted (Jankowicz, 2004).

Process analysis is an examination done in context. It is about ignoring the grid results for a time and reflecting on the interview itself, focusing on the process by which the information was obtained. The purpose is to provide background information for other analyses that will be used (Jankowicz, 2004). Notes were made on each respondent covering things like the venue that was selected, which included home and office settings, coffee shops, martini bars; how the respondent reacted to the reasons for the grid, most respondents welcomed this interest and attention from their financial advisory firm; how they felt about the process, for some respondent's element and construct elicitation came with ease while other respondents stopped to pour a drink as they struggled to reflect in this way or experienced the process as repetitive. Notes also included comments and correspondence post interview from the respondents.

The next step was to read the grid as a whole to gain familiarity with all that it encapsulated. This is known as an eyeball analysis (Jankowicz, 2004). Inferences were noted on how the respondents think about the role of wealth in their experience of quality of life by focusing on what constructs were used in making sense of the topic and interpreted in light of the process analysis already conducted.

After this descriptive phase, the constructs of each grid were categorized according to the meanings they express (Jankowicz, 2004). The categories are derived from the constructs themselves, by looking at them systematically and identifying the various themes they express. This way of categorizing constructs is called the bootstrapping technique (Holsti in Jankowicz, 2004). Using this technique each construct is taken as the unit of analysis and is compared with others and if an item is in some way like the first item, the two are placed together under a single category created for them at that very moment. If a construct is different to the first item, they're put into separate categories which often resulted in a redefining of existing categories. The process continues until all constructs are classified. This is known as core categorization procedure. Examples of categories included security, family, self-actualization. If there were any unclassifiable items they were placed in a category titled "miscellaneous" with the goal that no more than $5 \%$ would be regarded as such.

To ensure that the category system is not highly idiosyncratic but rather that it makes sense to others, it is important to build in a reliability check. For the category system to be considered reliable it should be stable in that the categories and constructs within categories would remain the same if the procedure was repeated a number of times. It should also be reproducible in that others would make the same sense of the constructs and finally there should be accuracy in that category definitions are consistently applied (Jankowicz, 2004). Reliability is enhanced by following the bootstrapping technique using the core categorization procedure explained above as well as in the case of this study involving a colleague who independently replicated the core categorization procedure. Categories where then identified according to those that both the researcher and colleague agreed on and those on which there was disagreement. The meaning of categories was then negotiated until a revised category system with high reliability could be finalized. For example, "security" was added as a category for respondent A, and additional constructs were included under the "relationship" category for respondent A to further enhance how this category is understood by the respondent. For each respondent such changes were made. The reliability of the results was further verified by referring to the extensive field notes, correspondence with respondents' pre and post interview and earlier process and eyeball analyses.

\section{Personal Construction}

Core categories along with corresponding constructs, resulting from the bootstrapping technique, are outlined per respondent below. These core categories can be viewed as themes that represent and reflect the constructs of the respondents' mental models. Where appropriate, comments or notes made from the process and eyeball analyses have been integrated to enhance clarity and meaning. 


\section{Respondent A}

The role of wealth in the experience of quality of life is about:

1. Upward mobility: Wealth is largely about upward mobility which is measured by the improvement and upgrading of living circumstances. (...living in a better area, nicer home, better welfare, better schools, better environment, making contacts, dealing with a different level of person, college educated parents, just moving on up, establishing self, establishing relationships...)

2. Family: This focus on upward mobility is aimed specifically at improving the lives of his wife and children. A strong focus on providing materially for family in the belief that this will enhance their self-esteem (... better schools for kids, nicer home for wife and kids, enjoying home, better welfare for kids, children in better area, children having more comfort, kids feeling better about themselves, children feeling better about home, bettering my life and the kids lives, desire to make wife and kids' life better...)

3. Entertaining: Cash flow for entertainment for social purposes as well as building business is important (...kids entertaining, entertainment, less cash flow to entertain, making contacts...)

4. Relationships: Friendships and the perceptions of others are important and have changed during a (...transition that was not easy on kids) from old neighbourhoods to new ones on this "upward trajectory". One sees (...core friends, making new friends, envious friends) and a shift in feeling (...overly sensitive, uncertain, indecisive, pessimistic, about other people's perceptions) to (... not caring about other people's perceptions, no fear, confident, wanted it done, determined I knew this is what I wanted)

5. Security: Wealth provides financial security (...by taking away pressure of paying monthly bills, security for retirement by not going into more debt, cash flow for entertaining, freedom to do more things ..)

6. During the interview respondent A came to the realization that he does not enjoy the business he is in ( ...not liking the business I run, escaping from the business I do, core business, hearts not in the business, ). What he loves is investing in real estate ( what I'd like to do, liking to invest in more real estate, exciting new deals.) In conversation he added that, his existing work allows him to fund his passion which is investing in real estate, but he believes he could not do this full time as "there is no cash flow in real estate." He stated that "if I could beef up the core business so that I could invest in what I would like to do in the future," "if I could earn enough in my real estate I would leave my business." This (...lack of love and passion for the business) is perceived to be in direct conflict with his (...desire to make wife and kids' life better...). Although his existing business has allowed him the financial success to secure an environment and physical comfort level that is important to him and his family, his heart is no longer in the business. There is however, no strong imagination of a different future, rather a resignation with the present.

7. Miscellaneous: (...intertwined relationship - business; what I wanted to do - did not have to do.)..

\section{Respondent B}

The role of wealth in the experience of quality of life is about:

1. Security/Protection: Wealth provides security and protection in the sense that there will be no danger in the future, but rather a status quo future. (...more meaning in terms of security blanket, security, nurture, protection, protected, being spoken for, never will be danger in the future, ...) whereas a lack of funds causes (...fear, insecurity, feeling vulnerable, me out in the world having to be a big girl unprotected, might be danger in the future, alone in the world...). It is therefore important one can "track money."

2. Acceptance and empowerment: Wealth is an indicator of success to others and enables one to do whatever they desire. Available wealth means external acceptance (... total acceptance by an outside force, external acceptance: whatever
I want to do, permissive) and is experienced as empowering (...empowers me, exhilarating, positive energy) whereas a lack of funds means (...critiquing by an outside force, external force runs my life, disempowers me.) and is associated with (...guilt, "funny" feeling, exhausting). Availability of funds "speaks to what shaped my life."

3. Maturity: Raised in a financially privileged environment the respondent describes her youth of financial abundance as a different, more positive time (...beginnings, youthful experience, idealism, youth, wish to be here, blissful, utopian, happier times, pleasure, where I like to be...) and with maturity and a company that started losing money we see (... maturity in who I am, realism, maturity, realism, hell, sad, pain, scary,... ) there is a need then to escape this situation ( always finding a way to escape, would love to escape and ignore, want to forget, escape, break from reality)

4. Conflicted responsibility: The respondent is co-responsible for the success of a company and talks about wanting to escape this situation. There is a want to break from the reality she finds herself in, to escape her present for a romanticized past. These feelings conflict with her need to consider others within the company and her family who she feels responsible for. (...about self gratification, me only considering me) versus (being responsible to someone other than myself, having to consider something other than me.) Another conflicted responsibility area is entitlement (earned these, entitled to these, can explain this, easier to take responsibility for this) when things are going financially well as opposed to (given this, don't own this, can't explain this, can't take responsibility for this) when things are financially not going well.

5. Miscellaneous: (bonding - environment; takes more energy no energy)

\section{Respondent C}

The role of wealth in the experience of quality of life is about:

1. Self-actualization: Material items that decline in value when purchased offer little value. If wealth allows (...self improvement, improve life, a way of moving on in my career, and a potential to make more money, greater skills to earn more money) then there is (long term gratification, personal gratification, lasting gratification,) this as opposed to spending on material items which are seen as (frivolous, selfcentered, less savings, more material, immediate gratification, creating an impression to others, things that decline in value when bought, less sustained pleasure, materialistic, wasteful, impulsive, felt somewhat foolish, no lasting value, impulsive buying, hurt cash flow, detrimental in long term, didn't improve life...)

2. Rational decision making: All financial transactions require careful consideration to ensure that the results have lasting value and improve cash flow. If decisions relating to money have (...lasting long term value, long term gratification, lasting benefit and improve cash flow) then they make (...financial, economic sense, ) even if that involves (... sacrifice for long term benefit, a lot of hard work as a result of the decision,). These types of decisions need (...more deliberation, more control, in control of transactions, certainty with what I was buying, thought out...). If this is the case then (...more satisfaction as I think back, feeling good about self, felt I made a good decision, )

3. Provision: Financially providing for those he is responsible for is important to the respondent. (... benefit to more than me, benefit to others, greater impact on me and those that I am responsible for) whereas money spend on self is seen as (...self centered, self pleasure, benefit to only me...)

4. Miscellaneous: ( buying cars - selling something; can make the same mistake twice - one time opportunity)

\section{Respondent D}

The role of wealth in the experience of quality of life is about: 1. Short term-gratification: Wealth is only good for the 
happiness it can bring you and this respondent experiences this happiness in the spending of money and the immediate positive effect of the spending. The analogy used during the interview was "... until you actually smoke the cigar you haven't completed the full course ... money must complete its cycle...money is only good for the happiness it can bring you." This was supported by the following constructs, (... instant gratification, spend profits, used right away, created additional happiness, immediate positive effect, ... ) as opposed to long term investments where (...money just there, didn't turn into happiness, just added to my portfolio,)

2. Relationships: Wealth is a means to bring joy into relationships (... brought happiness to others through utilization of money, resulted in enjoyment to the people I was connected with, combining family and finance in a positive way...)

3. Fun: Links to short term gratification as wealth and the spending of it is an enabler to have (...fun, enjoyable experience, fun event...)

4. Affirmation of self: The making of money is an indicator of success. (...feeling good about self, caused feeling of pride)

5. Luck: The making of many is also often seen as a function of luck (... part of being employed and luck, right place at right time, being part of the right team, did nothing to create, unexpected, right place at the right time...)

6. Risk averse: (...no financial risk, small amount of risk, no risk, could have been less painful with more discussion about the risks)

7. Financial gain: profit was a theme throughout: (... resulted in a profit, profit to portfolio, profit, resulted in a profit...)

8. Miscellaneous: (windfall - outfall; Pittsburgh - New Jersey)

\section{Respondent E}

The role of wealth in the experience of quality of life is about:

1. Duty and responsibility: He is very aware of his public responsibility to others through the establishment of a fund that supports individuals achieve their dreams and the financial support of a local arts organization. The constructs that support this (... for other people, long term good for other people, giving back, connecting to community, decisions about community, decisions about giving, public choices, our own pleasure at giving, public - doing it for many, meeting expectation - fulfilling a role, connection) as opposed to spending on self which is considered ( selfish, temporary hedonistic about pleasure, taking, separation from community both physically and symbolically, about self, indulgence, separation

2. Intimate Relationships: In the interview he stated that "your wealth resides in your relationships,...can't be desensitized to great relationships ...meaning comes from being a father, son, boss, spouse...your armor comes from connection to others specifically family and friends. "The constructs to support this... (connection, relationships, intimacy, close relationships, point to point relationship, one-to-one, bonding, private, intimate, trust and opportunity, ...)

3. Decision making: becomes important as a result of the complexity what wealth brings to life (... involves assessment, information and judgment, complex multiple parameter decision, planned, proactive, )

4. Miscellaneous: ( positive - negative experience)

\section{Respondent F}

The role of wealth in the experience of quality of life is about:

1. Self-actualization/accomplishment: (...rise to whatever I need as the need arises, emotional well-being, accelerate personal growth, about desires, goals in the broader context of family, friends, world, recognition that dreams are achievable, see my destiny fulfilled, striving for fulfillment, living life completely...)

2. Intimate relationships: His perception that his work success was in fact driven by a need for intimacy, he was not experiencing intimacy in his relationships and therefore sought to find it in his company (... confused intimacy, thirsting for intimacy, skill to achieve intimacy, desperation for intimacy, )

3. Protection: As a young boy he lost his father and when he reflects on that event we see (... fear, desperation, weakness, dependency, neediness...) and now in his current financial situation we see (...well defended, protected, strength, selfsufficient, financial independence...)

4. Freedom: wealth is about freedom, (...having no bounds, having whatever I desire, releasing me to pursue what is most important to me, infinite choice, boundless opportunity, to climb out of prison, left the prison gates, ) as opposed to a time when resources were limited (...making do with what one has, making peace with what I have, de-materializing, focus on most essential, food shelter clothing,

5. Role of father: His father's untimely death was linked to financial insecurity. His financial security allows him to be father in a different way (...found father, finding the father I always wanted and sharing it, my own dad)

6. Complexity: Previously there was a simplicity linked to building a company, paying a mortgage, now is a complex (...more complex time) as there is unbounded freedom to pursue what is most important to him but this still remains not clearly articulated or defined.

7. Miscellaneous: (decision point - slippery slope; certainty abruptness - boiling a frog one degree at a time)

\section{Respondent G}

The role of wealth in the experience of quality of life is about: In the interview there was movement between "two worlds" that the respondent has inhabited. The first, a financially privileged world that he was born into, and returned to at a later stage in his life as a result of his inheritance and personal financial success in his career. This world of financial abundance is alienating as a child and as an adult. Whereas he spent time during his twenties in a unionized, financially less privileged but in his mind more inclusive environment and it was here that he experienced and valued social solidarity for the first time and felt engaged.

1. The world of abundant money (...upper crust, exclusive, clean, money and power, ). This world is a world of authority (which I view as authority figures, authority, authority) complexity (high level, abstract, less well defined, uncertainty, sense making, analysis) and isolation (...very interior, isolated). Here it is about (who you are and looking like you belong) and being constantly judged (so conscious of self, overheads are high, have to hustle each time, hugely responsible for everything, jury is always out) and also associated with (right wing political camp, social circumstance).

2. The other world is associated with a unionized environment from when he was younger. It was here he experienced social solidarity. It was a world that was (...middle class, dirty but good) with no real authority figures (...no authority figure, boss not being an authority figure, kind of responsibility that does not include authority) The work is (...low level, clean and well defined, not being responsible for stuff at a high level, situation was taking care of me, I was not responsible, not having to make sense of the situation, work was quiet easy, know what is expected of you and do it). Here he was ( engaged with exterior world) there was a (net, a set of hands support from the community, showed there is an entire community structure to keep you safe and off the street, a social agreement, inclusive, ). This world is associated with (a left wing political camp). It was about (poverty and happiness.)

3. Miscellaneous: ( never leaves you - only when "on the dock")

\section{Interpretation and Sense-making}

From the feedback of the seven respondents one sees that although wealth has a highly individualized and personalized meaning in how it shapes the experience of QOL, common 
themes do emerge. Wealth allows respondents material well being in that their basic physical comfort needs are met which enhances the experience of quality of life. However, as these needs are saturated respondents are motivated to explore their needs around growth and relatedness, which include complex questions and decisions for respondents around who they are, what they would be, what it is that they value and where and with whom do they find love and experience community. Questions that essentially have to do with one's identity. Wealth influences how the respondents establish, maintain and verify their identity. When wealth assists in maintaining and verifying the most valued aspects of identity, quality of life is enhanced.

The results from these interviews are interpreted in detail below in view of and contextualized by the existing research on wealth, the semi-affluent investor and their experience of quality of life. QOL as previously explained is determined by the constellation of individual conditions of life (which include security needs and social needs) and components of subjective well being which has to do with the assessment by the individual of his/ her life and life in general. Together these are the components of QOL (Zapf, 1987).

If one looks initially at the dimension of security needs which are about "having" and include such conditions as income, education, health, accommodation and work (Zapf, 1987) one can draw comparisons to the "deficiency needs" of Maslow (1999) and the "existence needs" of Alderfer (1972), which have to do with physiological and safety needs. Satisfying these individual security needs is a role that wealth plays in the experience of quality of life. Material wealth allows respondents to buy homes in the areas they choose, fund children's education, entertain, provide security and protection and have fun in the way they choose to. This enhances their experience of quality of life.

According to Zapf's (1987) definition, the other component of individual conditions that determine quality of life has to do with social needs. This includes family ties, social contacts and social and political participation; it is about loving as opposed to having. Again, comparisons can be made with Maslow's (1999) belongingness needs and Alderfer's (1972) relatedness needs which have to do with a person's need to interact with others, receive public recognition and feel secure around people.

Given the semi-affluent nature of the respondent group, many of the individual having needs are met, however many of the social needs are often perceived not to be satisfied, which may negatively influence the experience of quality of life. These social needs are reflected in the following constructs that were identified by a majority of the respondents to be important: family, relationships, intimate relationships, and social solidarity. The importance of these constructs in the experience of QOL is supported by the research of Diener and Seligman (2004, p. 1-31), who found that differences in a sense of well being are "less frequently due to income and more frequently due to factors such as social relationships and enjoyment at work". This type of relational wealth, according to Diwan (2000, p. 305) ". . . emanates from our interconnections with other human beings. It gives us inner strength and emotional security and defines our quality of life". Lane (1994) found that a satisfying family life is the most important contributor to well-being. Friendship ranked second. Although Lane finds that satisfaction with these relationships does not vary with income level and along with Diwan, Diener and Seligman concludes that money does not bring happiness, one sees within our respondent group that wealth does indeed influence and shape the nature and experience of these relationships. For example, respondent G's experience of isolation is associated with his material wealth. Another example is how respondent $\mathrm{E}$ uses his wealth to engage in the experience of community by funding causes and respondent A, C and D using wealth to bring "joy" into relationships through entertaining, having fun and the provision of goods. Wealth for respondent B also serves as an indicator of "external acceptance," recognition by others, whereas respondent $\mathrm{F}$ viewed wealth as a by product of his search for intimacy in relationships.

Srivastava, Locke and Bartol (2001) believe that past research that argues that the relative importance a person attaches to material wealth is negatively related to the experience of QOL, suffers from the theoretical problem of not including the different motives for making money. They found that the negative relationship between money importance and well being was due to two variables, the motive of social comparison (seeking power and showing off) and secondly overcoming self-doubt. This is reflected in the respondent group. Respondent A and B who focus strongly on material needs, security needs and external acceptance, discussed wanting to escape their situation and enter into something that provided more personal meaning. This is in comparison to the respondents who valued their wealth, not for what it buys but as an enabler, providing them with the freedom to self-actualize or as a token or indicator of achievement.

Yet studies in the United States continue to indicate that increased affluence and increased choice have in fact been accompanied by decreased well being (Schwartz, 2004). This speaks to the component of the earlier definitions of QOL that has to do with the assessment by the individual of his/ her life and life in general. Frankl (1984, p. 152), talks of every age as having its "collective neurosis" and needing its own psychotherapy to cope. The "existential vacuum" is a widespread phenomenon of the twentieth century, " ... no instinct tells man what to do, and no tradition tells him what he ought to do; sometimes he does not even know what he wishes to do ..." (Frankl, 1984, p. 128). The patient of today according to Erikson (1963) suffers most under the problem of what he should believe and who he should or might be or become. While the patient of early psychoanalysis suffered most under inhibitions which prevented him from being what and who he thought he knew he was. The establishment and maintenance of identity is one of the most important ongoing organized processes in modern life. When people can successfully maintain and verify the most valued aspects of their identity, they live longer, healthier and happier lives. Personal identity has in a sense become the source of meaning and purpose in a life no longer dictated by blood lines and tradition (Zuboff \& Maxmin, 2002). Burke (1996, p.141) adds “ ... at the heart of modern stress is the experience of failed or interrupted identity" and Bronson (2002) concludes that people who feel fulfilled focus on questioning who they really are and then connecting that understanding to work that they truly love.

One's personal identity is the answer to the question, who am I? (Polkinghorne, 1997). It is a coherent conception of the self, made up of goals, values, and beliefs to which a person is solidly committed. Identity is a complicated inner state which includes four distinct aspects (Erikson, 1963; Ewen, 1998):

1. Individuality: A conscious sense of uniqueness and existence as a separate, distinct identity

2. Wholeness and synthesis: A sense of inner wholeness and indivisibility.

3. Sameness and continuity: An unconscious striving for a sense of inner sameness and continuity between who you have been in the past, and who you are likely to be in the future. A feeling that one's life has consistency and is headed in a meaningful direction.

4. Social solidarity: A sense of solidarity with the ideals and values of some group. Feeling that one receives support and recognition from significant others.

Wealth appears to influence how the respondents' establish, maintain and verify their personal identity which in turn shapes their assessment of their experience of quality of life. 
For example respondent B's wealth which is now threatened, influences her experience of sameness and continuity. There is a want to break from the reality she finds herself in, to forget, to ignore; to escape her present for a romanticized financially abundant past. There is no articulation of any future only a present that collapses in an unbearable way. Equally wealth allowed her to feel there was external acceptance and now with a dwindling in reserves social solidarity is absent and there is no sense of indivisibility as she struggles with what defines her as a separate, distinct identity, what gives her individuality.

Respondent G struggles with where he belongs, experiencing an interruption in identity. He finds himself in a financially privileged environment which he experiences as exclusive and isolating. There is no sense of solidarity with the ideals and values of this group nor any experience of support and recognition from members of this group.

Upward mobility measured by the improvement of living circumstances for both his family and himself is important for Respondent A. Yet he struggles with how to move forward in a more meaningful direction, connecting what he loves to the work he would do, without threatening the material achievements he values. There is no strong imagination of a different future, rather more of a resignation with the present, a curtailing of who he imagines himself to become, which negatively influences the experience of quality of life.

Respondent's C and F, value their wealth for the freedom it gives them to self actualize to live out their identities even though their goals are not always clearly defined.

Wealth then is perceived to allow respondents the ability to live their identity, to be who they imagine themselves to be even if what that is, is not always clearly defined. Equally, a lack of wealth can allow respondents to feel impeded in living out who they imagine themselves to be. Wealth can also cause identity confusion in that respondents may see themselves in a particular way and then as a result of a perceived abundance or absence of wealth are forced to see or redefine how they understand themselves. Wealth tends to influence the respondent's ability to be their identity or not which in turn shapes their assessment of their experience of quality of life.

\section{Conclusion}

Wealth satisfies material needs and then instigates the exploration of non-materialist needs. Respondents enjoy their "things" but place a value on the quality of the lives they lead in which those possessions play a part. They all seek meaning not just security and comfort. Wealth influences how this meaning can be found and lived, by enabling or inhibiting respondents to be who they imagine themselves to be. Wealth therefore shapes the respondent's sense of self, their identity. This then influences how comfortable or settled the respondents' feel in their worlds, their overall happiness or satisfaction with their life.

\section{Recommendations}

Financial advisors could consider new process approaches in their attempt to tailor their advice to each client's world view.

Using the Repertory Grid Technique as outlined in this study as the first step in any financial planning process would allow the advisors to understand the client's important personal constructs in terms of the role of wealth in their experience of QOL. Data from these interviews provides a way to operationalize QOL by allowing advisors to know what is important to each individual client, what they value, what gives them meaning, their concerns. Using this information as a starting point financial advisors will be able then to assist clients in using their wealth to improve their lives. For example, advisors could assist Respondent A in devising a plan that would allow him the cash flow and security he needs to provide for his family while at the same time releasing him to follow his passion for real estate as a full time business venture.

A similar yet more intensive option to consider is the development of a "unique process" that goes to the heart of the client's identity. A theoretically, philosophically and psychologically sound process supported by qualified people, that begins by assisting a client in defining who they are and what is important to them, as well as who they would want to be. The purpose of this would then be to provide an integrated and meaningful financial plan that supports the client's identity and imagination of the future.

There are a number of reasons why financial advisory firms should consider these routes. In the past it was the clergyman, the physician or the psychiatrist who was most privy to people's secret lives, their fears, desires and anxieties. However, this role is now being more and more occupied by financial advisors as they ask questions that deal with a wide range of personal and financial subjects (Needleman, 1983). Sullivan (2004, p. 2) believes that financial services clients will be willing to pay an upfront fee to go through a system during which they are able "to transform their sense of direction, confidence, and capability related to their futures". Clients who, as indicated previously, are wanting help in living an "ever more individuated life in an ever more complex environment ..." they want to buy something that has never before been for sale namely, "support in the invention and sustenance of a unique life" (Zuboff \& Maxmin, 2002, p. 172). From a market perspective, high net worth households control between six to eight trillion dollars in assets that could generate fifty billion dollars annually of recurring advisory fees, one of the most attractive kinds of revenue for financial advisory businesses (Hurley et al., 2004, p. 5).

\section{Suggestions for further research}

A next step would be to implement such processes that assist clients in defining who they are and what is important to them, as well as who they would want to be. To then provide integrated and meaningful financial plans that support the client's identity and imagination of the future and then explore whether the clients' experience of quality of life is enhanced as well as whether their perception of experience of service from the financial advisory firm is enhanced. It would also be important to explore how the financial advisors experience such a process. Do they believe that their financial advice is sounder and how did this process shape their experience of their own quality of life and meaning of work? It would be important for the financial advisory firm to explore the profitability of such a process as well as how the nature of financial investments and products needed may change as a result of the process.

\section{REFERENCES}

Alderfer, C.P. (1972). Existence, relatedness, growth. New York: Free Press.

Babbie, E. and Mouton, J. (2003) The practice of social research. Cape Town: Oxford University Press.

Bernheim, J. (1999). How to get serious answers to the serious question: How have you been?: Subjective quality of life(qol) as an individual experiential emergent construct. Bioethics. 13, 3-4.

Bronson, P. (2002). What should I do with my life? New York: Random House

Bulazo, S. (2004). Interview conducted by Meyer, L. 20 December 2004, Pittsburgh, USA

Burke, P.J. (1996). In B. Kaplan (Ed). Psychosocial stress: Perspectives on structure, theory, life course, and methods. San Diego: Academic Press.

Diener, E. and Seligman, M.E.P. (2004) Beyond money: Toward an economy of well being. Psychological Science in Public Interest. (5)1, 1-31. 
Diwan, R. (2000). Relational wealth and quality of life. Journal of Socio-Economics. (29)4, 305-341.

Dressel, J. (2004). Interview conducted by Meyer, L., 9 April 2004, Pittsburgh, USA

Erikson, E. (1963). Childhood and society. New York: Lawrence Erlbaum

Ewen, R.B. (1998). Theories of personality. Mahwah: Lawrence Erlbaum.

Farquhar, M. (1995). Elderly people's definition of quality of life. Social Science and Medicine. 41 (10), 1439 - 1446.

Finn, D.R. (1992). The meanings of money. American Behavioral Scientist. (35) 6, $658-668$.

Frankl, V.E. (1984). Man's search for meaning. New York: Simon \& Schuster.

Harper, A. \& Power, M. (1998). Development of the World Health Organization WHOQOL - Bref quality of life assessment. Psychological Medicine. 28 (3), 551 - 558.

Heyligen, F. (1992 ) A cognitive - systemic reconstruction of Maslow's theory of self-actualization. Behavioral Science. 37, 39-58.

Heyligen, F. \& Bernheim, J. (2000). Global Progress 1: Empirical Evidence for ongoing increase in quality of life. Journal of Happiness Studies. (1) 323-349.

Hurley, M.P., Fuller, T.G., Kanner, Y.N., Stroh,J.K., Jiede T.M., Dow, S.R. \& Kobos, P.F. (2004). The future of the financial advisory business and the delivery of advice to the semi-affluent investor - part 1. Available: http://www.undiscovered managers.com/Future\%20of\%20the\%20Financial\%20 Advisory\%20Business.pdf. [Accessed 3 April 2004]

Jankowicz, D. (2004). The easy guide to repertory grids. Chichester: John Wiley \& Sons.

Kelly, G.A. (1963). Theory of personality: The psychology of personal constructs. New York: W.W. Norton \& Company.

Kelly, P. (2002) Revisiting Maslow. Workspan. 45, 50-56.

Lane, R.E. (1994). Does money buy happiness? Current. 360, $27-$ 31 .

Maslow, A.H.(1999) Toward a psychology of being. New York: John Wiley and Sons.
Miles, M.B. and Huberman, A.J. (1997). In Swanson, R.A. and Holton, E.F.(Ed). Research handbook. San Francisco: BerrettKoehler.

Needleman, J. (1983). Money and the meaning of life. New York: Doubleday.

Polkinghorne, (1997). Phenomenology and Narrative Psychology. Proceedings of the Fourteenth Annual Symposium of the Simon Silverman Phenomenology Center. Pittsburgh, USA. pp $32-67$.

Roberts, E.B. \& Frohman, A.L. (1978). Strategies for improving research utilization. Technology and Review, 80 (5), 32-39.

Schurink, W.J. (2004) Qualitative research: Introducing key features of an integrative approach to Social Science. Unpublished research methodology course notes. Johannesburg: Rand Afrikaans University.

Schwartz, B. (2004). The Tyranny of Choice. Scientific American, 290 (4), 70-75.

Slowik, J.S., Hurley, M.P., Kanner, Y.N., Fuller, T.G., Boudreaux, C.L., Cortez, S.E., Mailibayeva, Z. and, Pan, P. (2000). The future of the financial advisory business part 11: Strategies for small business. Available: http://www.undiscoveredmanagers. com/Strategies_for_Small_Businesses.pdf ([Accessed 3 April 2004]

Smith, A.E. (2000). Quality of Life: a review. Education and Ageing. 15 (3), 419 - 435

Srivastava, A.; Locke, E.A. \& Bartol, K.M. (2001). Money and subjective well- being; Its' not the money, it's the motives. Journal of Personality and Social Psychology. 80 (60). 959 - 971.

Strategic Coach. (2004). Creative destruction. Available: http://www.strategiccoach.com. [Accessed 5 May 2004]

Valli, L. (2004). Interview conducted by Meyer, L., 27 January 2004, Pittsburgh, USA.

Zalewski, W. (2004). Interview conducted by Meyer, L., 27 January 2004, Pittsburgh, USA.

Zapf, W. (1987). Modernization, welfare development and transformation. Berlin: Sigma

Zuboff, S. \& Maxmin, J. (2002). The support economy. New York: Penguin. 